\title{
CISTADENOCARCINOMA RENAL E DERMATOFIBROSE NODULAR EM CÃES PASTOR ALEMÃO: 4 CASOS
}

\author{
RENAL CYSTADENOCARCINOMA AND NODULAR DERMATOFIBROSIS \\ IN GERMAN SHEPHERD DOGS: 4 CASES
}

\section{Ingeborg Maria Langohr ${ }^{1}$ Luiz Francisco Irigoyen ${ }^{2}$ Mônica Weissmann Seabra Salles ${ }^{3}$ Glaucia Denise Kommers ${ }^{3}$ Claudio Severo Lombardo de Barros ${ }^{4}$}

RESUMO

São descritos quatro casos da síndrome cistadenocarcinoma renal-dermatofibrose nodular em Pastor Alemão. Todos eram cães machos, com idades entre 6 e 10 anos. Os aspectos clínicos incluíam hematúria e retenção urinária, emagrecimento progressivo, anorexia, vômito, polidipsia $e$ dificuldade respiratória. Em um animal, foram observados múltiplos nódulos recidivantes na pele. Três cães tiveram morte espontânea e um foi submetido à eutanásia. Os principais achados de necropsia incluíram nódulos multifocais ou coalescentes na pele e múltiplos nódulos, muitas vezes císticos, em ambos os rins. Na avaliação histológica, observaram-se dermatofibrose nodular na pele e cistos, hiperplasia, displasia e neoplasia de células epiteliais dos túbulos renais. As neoplasias foram classificadas como cistadenoma em um dos casos e como cistadenocarcinoma nos outros três. Metástases foram observadas em dois casos: no figado, no baço e no pulmão em um cão e no linfonodo renal em outro.

Palavras-chave: doenças de cão, Pastor Alemão, neoplasias, rim, dermatofibrose nodular, pele, doenças hereditárias.

\section{SUMMARY}

Renal cystadenocarcinoma-nodular dermatofibrosis syndrome of German shepherd are described in four 6 to 10-yearold male dogs. Clinical findings included hematuria and urinary retention, progressive weight loss, polydipsia, anorexia, vomiting, and respiratory distress. Several recurrent skin nodules were observed in one of the dogs. Three dogs died spontaneously and one was euthanatized. Main gross findings included multifocal to coalescent skin nodules and multiple nodules, mostly cystic, in both kidneys. Microscopically there was nodular dermatofibrosis in the skin and renal cysts, dysplastic, hyperplastic and neoplastic changes of the renal tubular epithelium. The neoplasms were classified as cystadenoma in one case and cystadenocarcinoma in the other three. There were metastases in the liver, spleen and lung of one dog and in the renal lymph node in another one.

Key words: diseases of dog, German shepherd, neoplasia, kidney, nodular dermatofibrosis, skin, hereditary disorders.

\section{INTRODUÇÃO}

Neoplasias renais primárias são raras em todos os animais domésticos (NIELSEN \& MOULTON, 1990; MAXIE, 1993). Sua freqüência varia entre as espécies animais e, em cães, representa de $0,3 \%-1,0 \%$ de todas as neoplasias primárias (BASKIN \& DePAOLI, 1977; NIELSEN \& MOULTON, 1990). Uma condição especial, em que cistadenocarcinomas renais (CR) multifocais e bilaterais ocorrem concomitantemente com dermatofibrose nodular (DN) generalizada e, nas fêmeas, com múltiplos leiomiomas uterinos, tem sido descrita como doença rara e hereditária em cães, ocorrendo quase que exclusivamente na raça Pastor Alemão (SUTER et al., 1983; LIUM \& MOE,

\footnotetext{
${ }^{1}$ Médico Veterinário, Aluno de Mestrado do Programa de Pós-graduação em Medicina Veterinária, Área de Concentração em Patologia Veterinária. Universidade Federal de Santa Maria (UFSM), 97105-900, Santa Maria, RS. E-mail: ilangohr@hotmail.com. Autor para correspondência.

${ }^{2}$ Médico Veterinário, PhD, Professor Adjunto do Departamento de Patologia, UFSM.

${ }^{3}$ Médico Veterinário, Mestre, Professor Assistente do Departamento de Patologia, UFSM.

${ }^{4}$ Médico Veterinário, PhD, Professor Titular do Departamento de Patologia, UFSM.
} 
1985; COSENZA \& SEELY, 1986; GILBERT et al., 1990; VILAFRANCA $\boldsymbol{e t}$ al., 1994; MOE \& LIUM, 1997a,b; WEISS \& TEIFKE, 1999; MOE $\boldsymbol{e t}$ al., 2000). Os sinais clínicos apresentados pelos cães afetados são, muitas vezes, inespecíficos e incluem apatia, anorexia, emagrecimento progressivo, polidipsia, vômito, diarréia e outros sinais de uremia e dependem da extensão do envolvimento renal (LIUM \& MOE, 1985; COSENZA \& SEELY, 1986; KLEIN et al., 1988; NIELSEN \& MOULTON, 1990; MOE \& LIUM, 1997a). Hematúria, um dos aspectos clínicos mais consistentemente associados a carcinomas renais em humanos, não é comumente relatada nos cães afetados (COSENZA \& SEELY, 1986; MOE \& LIUM, 1997a). As lesões nodulares da pele, se localizadas entre os dígitos e as almofadas digitais causam, muitas vezes, claudicação (COSENZA \& SEELY, 1986; GILBERT et al., 1990; SCOTT et al., 1996). Os nódulos, geralmente de 0,5 a $5,0 \mathrm{~cm}$ de diâmetro, localizam-se primariamente na porção distal dos membros, mas também podem ser observados na cabeça e no tronco. Na maioria das vezes, os nódulos são recobertos por pele normal, embora possam ocorrer alopecia, hiperpigmentação e ulceração (SUTER et al., 1983; SCOTT et al., 1984; COSENZA \& SEELY, 1986; GILBERT et al., 1990; SCOTT et al., 1996).

As lesões observadas na necropsia compreendem múltiplos nódulos cutâneos firmes diagnosticados como nevos de colágeno ou dermatofibrose, lesões renais císticas bilaterais, de tamanho variável e tipicamente múltiplas, e leiomiomas múltiplos no útero (LIUM \& MOE, 1985; COSENZA \& SEELY, 1986; GILBERT et al., 1990; VILAFRANCA et al., 1994; MOE \& LIUM, 1997a). Metástases em linfonodos esternal cranial, paraórtico, renal e bronquiais, fígado, pulmão, superfícies serosas (pleura, peritônio), baço, pâncreas e ossos têm sido relatadas (SUTER $\boldsymbol{e t}$ al., 1983; COSENZA \& SEELY, 1986; MOE \& LIUM, 1997a).

O exame histológico do córtex renal mostra cistos não-neoplásicos que podem chegar a $25 \mathrm{~cm}$ de diâmetro e contêm líquido claro a marrom escuro, nódulos hiperplásicos e displásicos, adenomas e cistadenocarcinomas. Tem sido descrita uma variante oncocítica incomum de carcinoma renal cromofílico-eosinofílico nos animais afetados pela síndrome CR/DN (VILAFRANCA et $\boldsymbol{a l}$., 1994). Os nódulos da pele consistem de fibras colágenas densas entremeadas por fibroblastos normais esparsos; os tumores uterinos são leiomiomas caracterizados histologicamente por feixes entrelaçantes de células musculares lisas (LIUM \& MOE, 1985; MOE \& LIUM, 1997a).

A síndrome $\mathrm{CR} / \mathrm{DN}$ é de origem hereditária autossômica dominante, de penetrância completa (JÓNASDÓTTIR et al., 2000). Segundo WEISS \& TEIFKE (1999), afeta somente os descendentes do cruzamento de "Jutta von Colonia Agrippina" e "Fred zu den sieben Faulen" (1950). É um dos poucos exemplos de tumores hereditários de ocorrência natural em mamíferos não-humanos, não havendo correspondência exata dessa condição em pessoas, mas os padrões clínicos lembram enfermidades associadas a mutações em genes supressores tumorais (JÓNASDÓTTIR et al., 2000). Relatos recentes sobre o mapeamento genético de $\mathrm{CR} / \mathrm{DN}$ localizando o gene em uma pequena região do cromossomo canino 5 descrevem essa síndrome tumoral como sendo a primeira em mamíferos a ser mapeada em uma espécie diferente da humana e da murina (JÓNASDÓTTIR et al., 2000). Esses autores sugerem que CR/DN é causada por um gene supressor tumoral não identificado anteriormente ou por um gene anteriormente identificado com associação desconhecida com síndromes tumorais hereditárias.

Descrevem-se quatro casos de CR/DN em cães da raça Pastor Alemão necropsiados na Seção de Patologia Veterinária da Universidade Federal de Santa Maria (UFSM) no período de 1994-2000, com caracterização do quadro clínico, dos achados de necropsia e de histopatologia. O tratamento e a importância da profilaxia da síndrome também são discutidos.

\section{MATERIAL E MÉTODOS}

Entre 1994 e 2000, foram diagnosticados quatro casos de neoplasias renais associadas a nódulos cutâneos em cães Pastor Alemão. Para determinar a natureza específica dessas lesões e sua prevalência entre os cães dessa raça necropsiados neste período, foi realizada uma revisão dos arquivos do Setor de Patologia Veterinária da Universidade Federal de Santa Maria em que se verificou o número de cães da raça Pastor Alemão necropsiados e a idade, o sexo, os sinais clínicos e as lesões macro e microscópicas observadas em animais afetados.

\section{RESULTADOS}

No período estudado, quatro de 103 $(3,88 \%)$ cães necropsiados da raça Pastor Alemão, todos machos, apresentavam tumores renais multifocais e bilaterais concomitantemente com dermatofibrose nodular generalizada (Tabela 1). 
Tabela 1 - Cistadenocarcinoma renal e dermatofibrose nodular em cães Pastor Alemão. Idade e sinais clínicos dos quatro cães afetados.

\begin{tabular}{|c|c|c|c|}
\hline Cão & Protocolo & Idade (anos) & Sinais clínicos \\
\hline 1 & Vn-33-94 & 10 & $\begin{array}{l}\text { Hematúria; retenção urinária; bexiga tensa e } \\
\text { aumentada de volume. Edema subcutâneo no } \\
\text { membro pélvico direito. Morte espontânea. }\end{array}$ \\
\hline 2 & Vn-251-94 & 7 & $\begin{array}{l}\text { Emagrecimento progressivo há um mês. Tosse e } \\
\text { dispnéia. Há três dias não se alimentava. Teve } \\
\text { vômito dois dias antes. Morte espontânea. }\end{array}$ \\
\hline 3 & Vn-85-96 & 8 & $\begin{array}{l}\text { Nódulos na pele há dois anos. Retirados } \\
\text { cirurgicamente por três vezes, apresentaram } \\
\text { recidivas. O proprietário não soube informar a } \\
\text { respeito da natureza dos resultados das biópsias. } \\
\text { Embora estivesse clinicamente estável, sofreu } \\
\text { eutanásia. }\end{array}$ \\
\hline 4 & Vn-243-96 & 6 & $\begin{array}{l}\text { Estava solto no pátio, procurando água e com } \\
\text { respiração acentuada. O proprietário saiu às } 12 \mathrm{~h} \text { e, } \\
\text { quando retornou ( } 15 \mathrm{~h}) \text {, encontrou o cão morto. }\end{array}$ \\
\hline
\end{tabular}

avermelhado (Figura 2). No cão 4, havia $1.200 \mathrm{~m} \ell$ de sangue na cavidade peritoneal associado à ruptura de um dos cistos. Esse mesmo animal apresentava nódulos tumorais esbranquiçados firme-elásticos no fígado e no baço e o cão 2 , no linfonodo renal.

No exame microscópico da pele, observavam-se nódulos de proliferação exuberante e irregular de fibras colágenas na derme. Em alguns cortes, havia hiperplasia irregular da epiderme com hiperqueratose ortoqueratótica moderada, às vezes com incontinência pigmentar, ulceração do epitélio e infiltrado mononuclear. Paniculite necrosante crônica localmente extensa foi

$\mathrm{Na}$ necropsia, a pele dos quatro animais apresentava nódulos multifocais a coalescentes de 0,2 a $3 \mathrm{~cm}$ de diâmetro, de consistência firme, alguns recobertos por pele íntegra, outros com alopecia ou ulceração (Figura 1). A superfície de corte era lisa, esbranquiçada ou enegrecida. Os nódulos eram distribuídos na cabeça e nos membros, principalmente nos membros pélvicos. $O$ cão 1 apresentava edema subcutâneo difuso entremeado por áreas esbranquiçadas e filamentosas no membro posterior direito. Os rins dos cães 1 e 2 estavam acentuadamente aumentados de volume, com tamanhos variando de $16 \times 12 \times 5 \mathrm{~cm}$ a $30 \times 22 \times 7 \mathrm{~cm}$. Todos os animais apresentavam múltiplos nódulos de consistência flutuante, de 0,2 a $6 \mathrm{~cm}$ de diâmetro, que protruíam na superfície capsular do rim. $\mathrm{Na}$ superfície de corte havia cistos de até $5 \mathrm{~cm}$ de diâmetro contendo líquido límpido ou marrom

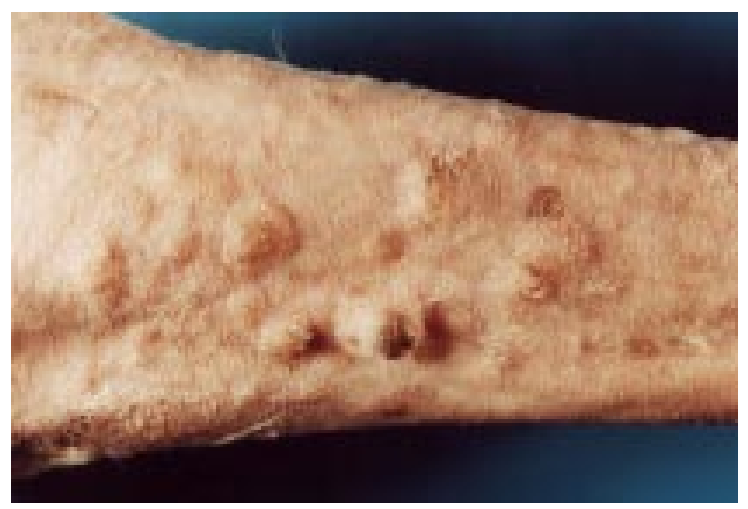

Figura 1 - Cistadenocarcinoma renal e dermatofibrose nodular em cães Pastor Alemão. Múltiplos nódulos cutâneos pequenos e firmes no membro torácico direito de um Pastor Alemão afetado pela síndrome neoplásica. observada no membro posterior direito do cão 1 . Nos rins, havia proliferação de células cúbicas arranjadas em estruturas adenóides, tubulares ou sólidas. As células tumorais eram maiores que as tubulares e tinham citoplasma homogêneo e fracamente eosinofílico ou finamente granular. Os núcleos eram redondos ou ovais, de tamanhos variados, com cromatina finamente granular ou condensada formando agregados maiores. Com freqüência, eram observadas grandes áreas císticas revestidas por epitélio cúbico alto formando projeções digitiformes, longas e tortuosas, orientadas para a luz dos cistos, que continham sangue, fendas de colesterol, restos celulares e macrófagos com ceróide. Extensas áreas de necrose e hemorragia ocorriam no parênquima tumoral. As neoplasias foram classificadas como cistadenoma no cão $3 \mathrm{e}$ como cistadenocarcinoma nos outros casos. Havia, ainda, glomeruloesclerose, fibrose intersticial,

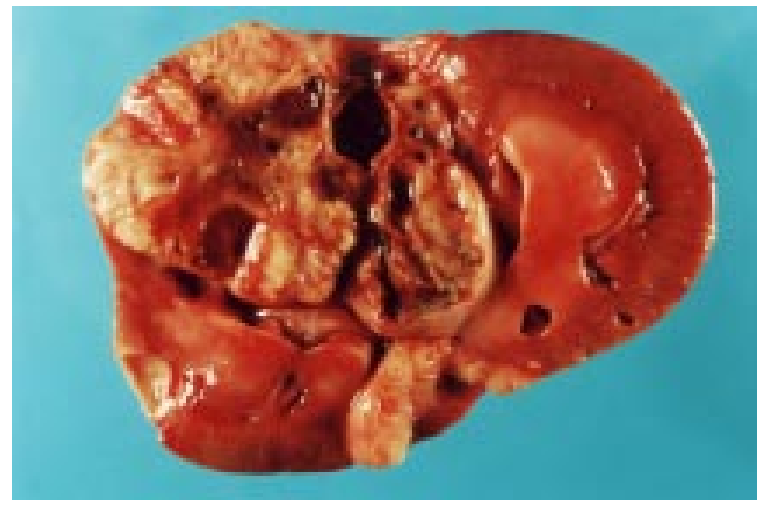

Figura 2 - Cistadenocarcinoma renal e dermatofibrose nodular em cães Pastor Alemão. Na superfície de corte, observa-se que o tumor ocupa um dos pólos do rim, comprimindo a pelve. 
dilatação do espaço urinário, calcificação da membrana basal tubular e da cápsula de Bowman, acentuada atrofia dos túbulos circunjacentes e presença de cristais birrefringentes na luz de numerosos túbulos.

O aspecto histológico das metástases e dos tumores primários era o mesmo. Embolias tumorais linfáticas e venosas eram vistas no fígado, no baço e nos pulmões do cão 4 e no linfonodo renal do cão 2 .

Nos cães 1 e 2, havia lesões relacionadas à uremia incluindo pneumopatia e gastropatia urêmicas. Achados incidentais incluíram megaesôfago, corpo estranho tubular firme de plástico com cerca de $20 \mathrm{~cm}$ no estômago, seminoma, broncopneumonia supurativa multifocal, endocardiose, lipofucsinose neuronal, prostatite crônica, e hiperplasias adrenocortical, da paratireóide e cística prostática.

\section{DISCUSSÃO}

A prevalência de cães Pastor Alemão que apresentaram a síndrome cistadenocarcinoma renaldermatofibrose nodular $(\mathrm{CR} / \mathrm{DN})$ nesse relato é corroborada por outros autores (LIUM \& MOE, 1985), sendo essa prevalência mais alta que a ocorrência de neoplasias renais primárias relatada em outras raças (LUCKE \& KELLY, 1976; BASKIN \& DePAOLI, 1977; NIELSEN \& MOULTON, 1990).

A média de idade dos cães afetados $(8$ anos) é a mesma dos cães com tumores renais primários esporádicos (LUCKE \& KELLY, 1976; BASKIN \& DePAOLI, 1977; NIELSEN \& MOULTON, 1990) ou afetados por CR/DN (SUTER et al., 1983; LIUM \& MOE, 1985; KLEIN et al., 1988; MOE \& LIUM, 1997a,b; MOE et al., 2000).

Os sinais clínicos dos animais desse estudo são os descritos para a condição em cães Pastor Alemão (LIUM \& MOE, 1985; COSENZA \& SEELY, 1986; KLEIN et al., 1988; MOE \& LIUM, 1997a). Dois dos quatro cães apresentaram quadro clínico compatível com envolvimento do trato urinário (anorexia, vômito, hematúria e retenção urinária). As lesões nodulares recidivantes de pele foram a única queixa do proprietário de outro animal. Situação semelhante tem sido descrita em cães afetados por CR/DN (SCOTT et al., 1984; COSENZA \& SEELY, 1986; GILBERT et al., 1990; VILAFRANCA et al., 1994; MOE \& LIUM, 1997a). A dificuldade respiratória e a "morte súbita" observadas no cão 4 eram provavelmente relacionadas com o hemoperitônio associado à ruptura dos cistos renais (LIUM \& MOE, 1985; MOE \& LIUM, 1997a).
Os quatro cães deste relato eram machos. De fato, parece haver uma maior prevalência de CR/DN em cães machos (LUCKE \& KELLY, 1976; BASKIN \& DePAOLI, 1977; KLEIN et al., 1988), embora isso seja contestado por alguns autores (LIUM \& MOE, 1985; MOE \& LIUM, 1997a).

A morfologia macro e microscópica dos nódulos cutâneos observada nos casos aqui relatados é idêntica à condição descrita como "dermatofibrose nodular generalizada" (SUTER et al., 1983; LIUM \& MOE, 1985; GILBERT et al., 1990; STEWART, 1990; VILAFRANCA et al., 1994; SCOTT et al., 1996; MOE \& LIUM, 1997a). Essa alteração afeta primariamente os membros, a cabeça, o pescoço e a região ventral do tronco; é composta por feixes irregulares de fibras colágenas densas com poucos fibrócitos (LIUM \& MOE, 1985; COSENZA \& SEELY, 1986; GILBERT et al., 1990; SCOTT et al., 1996; WEISS \& TEIFKE, 1999). Lesões cutâneas múltiplas aparentemente idênticas localizadas nos membros distais e na cabeça de cinco cães Pastor Alemão foram descritas como nevo de colágeno com base em biópsias de pele (SCOTT et al., 1984). Como não foi realizada a necropsia dos animais afetados, não se pode excluir que esses cães tinham a síndrome aqui relatada.

As lesões renais observadas na necropsia dos quatro cães desse relato eram típicas de $\mathrm{CR} / \mathrm{DN}$, consistindo de múltiplos cistos e nódulos tumorais bilaterais que protruíam do parênquima renal normal (SUTER et al., 1983; LIUM \& MOE, 1985; VILAFRANCA et al., 1994; MOE \& LIUM, 1997a; WEISS \& TEIFKE, 1999).

Em um dos casos aqui apresentados, havia edema subcutâneo no membro posterior direito. Essa alteração tem sido relacionada a impedimento do retorno venoso (GILBERT et al., 1990).

Pólipos pequenos e múltiplos na mucosa intestinal e proliferação multifocal de colágeno ao longo das fáscias musculares e na serosa da bexiga, embora considerados constantes nessa síndrome neoplásica (COSENZA \& SEELY, 1986; MOE \& LIUM, 1997a), não foram observados nos casos aqui descritos. É interessante notar, no entanto, que essas proliferações não causam qualquer sinal clínico e, mesmo na necropsia, pode ser difícil detectá-las (MOE \& LIUM, 1997a).

As alterações histológicas nos rins consistiam tipicamente de cistos, hiperplasia e displasia multifocais e de transformação neoplásica de células epiteliais tubulares renais. Os achados microscópicos de neoplasia renal típicos de adenoma em um dos animais afetados podem representar um estágio anterior ao desenvolvimento de um tumor 
maligno da mesma natureza, diagnosticado nos outros três animais. É descrito que as lesões renais podem progredir lentamente de cistos benignos a adenomas e, posteriormente, a adenocarcinomas (GILBERT et al., 1990).

A hiperplasia micropapilar do epitélio de revestimento da parede interna dos cistos renais, observada nos casos aqui descritos, é tida como um dos aspectos característicos de CR/DN (MOE et al., 2000). Os microcistos renais aumentam de tamanho com a idade (MOE \& LIUM, 1997b) e, como mencionado anteriormente, são considerados lesões precursoras de adenomas e carcinomas (GILBERT $\boldsymbol{e t}$ al., 1990; JÓNASDÓTTIR $\boldsymbol{e t}$ al., 2000; MOE $\boldsymbol{e}$ t al., 2000). Em uma ninhada de sete cães, resultante de um cruzamento teste, os sinais clínicos de enfermidade urogenital foram observados apenas um a três anos após a detecção dos primeiros cistos na tomografia computadorizada (MOE \& LIUM, 1997b). Essa alteração renal pode, portanto, ser usada como critério diagnóstico precoce da enfermidade em animais com predisposição à $\mathrm{CR} / \mathrm{DN}$.

A relação entre a proliferação de células epiteliais renais e a formação de cistos ainda não foi esclarecida (LIUM \& MOE, 1985). Há evidências de que as células epiteliais em proliferação podem causar obstrução local por bloqueio mecânico e dilatação subseqüente dos segmentos proximais. A tendência marcante de hemorragia e necrose nas proliferações papilares pode explicar a pequena quantidade de células neoplásicas revestindo os cistos grandes repletos de fluido escuro e coágulo de sangue.

A distribuição multifocal e predominantemente bilateral da proliferação de células renais nos cães afetados indica que os tumores tiveram uma origem multicêntrica primária, ao contrário dos tumores renais de ocorrência esporádica que são geralmente unilaterais e solitários, com ocasionais metástases no rim oposto (LIUM \& MOE, 1985). Em CR/DN há um relato de tumor renal unilateral (GILBERT et al., 1990). Nesse caso, entretanto, o rim com macroscopia aparentemente normal não foi submetido à avaliação histológica, não podendo ser excluída a possibilidade da ocorrência de lesões microscópicas.

A morte de três dos animais provavelmente se deveu aos tumores renais e suas complicações (incluindo uremia, metástases e ruptura de cistos) que, associados a complicações da dermatofibrose nodular e infecções secundárias da pele, têm sido relatados como a principal causa da morte natural ou por eutanásia nesses animais (MOE \& LIUM, 1997a).
Não há tratamento curativo ou profilático, exceto a excisão cirúrgica dos nódulos cutâneos (SCOTT et al., 1984; COSENZA \& SEELY, 1986; STEWART, 1990; SCOTT et al., 1996), nefrectomia unilateral de rins císticos benignos ou mais gravemente afetados pelo tumor (GILBERT et al., 1990; MOE \& LIUM, 1997a) ou a histerectomia para tumores uterinos em fêmeas (MOE \& LIUM, 1997a). Em cães com ascite e peritonite resultante da ruptura de cistos, deve-se fazer tratamento de suporte e paracentese abdominal (MOE \& LIUM, 1997a). O tratamento dos nódulos cutâneos pode não ser necessário, dependendo da sua localização e gravidade (COSENZA \& SEELY, 1986). A quimioterapia não foi avaliada nos cães desse relato, mas Paclitaxel tem sido recomendado para evitar a progressão dos múltiplos cistos renais (MOE \& LIUM, 1997a). O transplante de rim não é indicado por questões éticas e práticas (MOE \& LIUM, 1997a).

O avanço da doença pode ser lento; o prognóstico a longo prazo, no entanto, é reservado ou desfavorável por se tratar de uma enfermidade sistêmica (STEWART, 1990). É recomendável, pois, prevenir a ocorrência de $\mathrm{CR} / \mathrm{DN}$ alertando os proprietários de cães reprodutores para que não utilizem seus animais afetados para a reprodução quando o diagnóstico é confirmado. Para a detecção precoce de cistadenocarcinomas renais e o escrutínio de cães reprodutores, a técnica da tomografia computadorizada mostrou-se superior à radiografia simples e contrastada do sistema urinário. A utilização dessa técnica permite a detecção dos cistos renais já aos quatro a cinco anos de idade (MOE \& LIUM, 1997b). Outra opção é a biópsia renal, que, realizada em animais com menos de um ano de idade, permite determinar portadores de $\mathrm{CR} / \mathrm{DN}$ antes que sejam usados para reprodução (MOE et al., 2000).

\section{REFERÊNCIAS BIBLIOGRÁFICAS}

BASKIN, G.B., DePAOLI, A. Primary renal neoplasms of the dog. Vet Pathol, v.14, p.591-605, 1977.

COSENZA, S.F., SEELY, J.C. Generalized nodular dermatofibrosis and renal cystadenocarcinomas in a German shepherd dog. J Am Vet Med Assoc, v.189, n.12, p.1587$1590,1986$.

GILBERT, P.A., GRIFFIN, C.E., WALDER, E.J. Nodular dermatofibrosis and renal cystadenoma in a German shepherd dog. J Am Anim Hosp Assoc, v.26, p.253-256, 1990.

JÓNASDÓTTIR, T.J., MELLERSH, C.S., MOE, L., et al. Genetic mapping of a naturally occurring hereditary renal cancer syndrome in dogs. Proc Natl Acad Sci USA, v.97, n.8, p.4132-4137, 2000. 
KLEIN, M.K., COCKERELL, G.L., HARRIS, C.K., et al. Canine primary renal neoplasms: a retrospective review of 54 cases. J Am Anim Hosp Assoc, v.24, p.443-452, 1988.

LIUM, B., MOE, L. Hereditary multifocal renal cystadenocarcinomas and nodular dermatofibrosis in the German shepherd dog: macroscopic and histopathologic changes. Vet Pathol, v.22, p.447-455, 1985.

LUCKE, V.M., KELLY, D.F. Renal carcinoma in the dog. Vet Pathol, v.13, p.264-276, 1976.

MAXIE, M.G. The urinary system. In: JUBB, K.V.F., KENNEDY, P.C., PALMER, N. Pathology of domestic animals. 4.ed. San Diego : Academic, 1993. v.2. Cap.5. p.447-538.

MOE, L., LIUM, B. Hereditary multifocal renal cystadenocarcinomas and nodular dermatofibrosis in 51 German shepherd dogs. J Small Anim Pract, v.38, p.498$505,1997 \mathrm{a}$.

MOE, L., LIUM, B. Computed tomography of hereditary multifocal renal cystadenocarcinomas in German shepherd dogs. Vet Radiol Ultrasound, v.38, n.5, p.335-343, 1997 b.

MOE, L., GAMLEM, H., JÓNASDÓTTIR, T.J., et al. Renal microcystic tubular lesions in two 1-year-old dogs - An early sign of hereditary renal cystadenocarcinoma? J Comp Pathol, v.123, n.2-3, p.218-221, 2000
NIELSEN, S.W., MOULTON, J.E. Tumors of the urinary system. In: MOULTON, J.E. Tumors in domestic animals. 3.ed. Berkeley : University of California, 1990. Cap.10. p.458-478.

SCOTT, D.W., MILLER, W.H., GRIFFIN, C.E. Muller \& Kirk - Dermatologia de pequenos animais. 5.ed. Rio de Janeiro: Interlivros, 1996. 1130p. Cap.19: Tumores neoplásicos e não-neoplásicos: p.926-1054.

SCOTT, D.W., YAGER-JOHNSON, J.A., MANNING, T.O., $\boldsymbol{e} t$ al. Nevi in the dog. J Am Anim Hosp Assoc, v.20, p.505$512,1984$.

STEWART, L.J. Newly reported skin disease syndromes in the dog. Vet Clin North Am Small Anim Pract, v.20, n.6, p.1603-1613, 1990.

SUTER, M., LOTT-STOLZ, G., WILD, P. Generalized nodular dermatofibrosis in six Alsatians. Vet Pathol, v.20, p.632634, 1983.

VILAFRANCA, M., FONDEVILA, D., MARLASCA, M.J., et al. Chromophilic-eosinophilic (oncocyte-like) renal cell carcinoma in a dog with nodular dermatofibrosis. Vet Pathol, v.31, p.713-716, 1994.

WEISS, E., TEIFKE, J.P. Haut. In: DAHME, E., WEISS, E. Grundriss der speziellen pathologischen Anatomie der Haustiere. 5.ed. Stuttgart : Enke, 1999. Cap.15. p.484561. 